\title{
Avaliação do nível de aprendizagem com manipuladores sobre boas práticas de
}

\section{manipulação de alimentos}

\author{
Assessment of the level of learning from handlers on good food handling practices \\ Evaluación del nivel de aprendizaje de los manipuladores sobre buenas prácticas de manipulación \\ de alimentos
}

Recebido: 08/01/2021 | Revisado: 11/01/2021 | Aceito: 15/01/2021 | Publicado: 18/01/2021

\author{
Gesaildo Martins de Oliveira Júnior \\ ORCID: https://orcid.org/0000-0002-9564-8031 \\ Universidade Federal de Campina Grande, Brasil \\ E-mail: gesaildo@gmail.com \\ Jair Francisco de Lima Segundo \\ ORCID: https://orcid.org/0000-0002-8683-6065 \\ Universidade Federal de Campina Grande, Brasil \\ E-mail: jairlimasegundo@gmail.com \\ Heloísa Maria Ângelo Jerônimo \\ ORCID: https://orcid.org/0000-0002-3139-4589 \\ Universidade Federal de Campina Grande, Brasil \\ E-mail: helogero@yahoo.com.br
}

\begin{abstract}
Resumo
As Unidades de Alimentação e Nutrição (UANs) são responsáveis pela produção de refeições, cujo objetivo é atender as demandas nutricionais dos indivíduos. Dentro dessas unidades, têm sido verificado o aumento do número de doenças transmitidas por alimentos (DTAs), fazendo com que seja necessário maiores cuidados na manipulação de alimentos nesses locais. Nesse contexto, os funcionários que trabalham nesse campo, tornam-se potenciais ferramentas na transmissão dessas doenças através dos próprios alimentos. Devido a essa problemática, a ANVISA editou a RDC $n^{\circ}$ 216/04 que preconiza periódicas capacitações em Boas Práticas de Fabricação. Portanto, esse trabalho teve por objetivo avaliar o impacto do curso em BPF para manipuladores de alimentos de escolas e creches. O curso foi realizado no município de Picuí-PB, e foram contemplados todos os manipuladores de alimentos da rede pública municipal. Foram aplicados questionários de perfil sociodemográfico e de BPF com foco especial em higiene, em dois momentos, um antes e outro depois do curso. Após a realização do curso, foi verificado que 88,33\% pertenciam ao sexo feminino, $43,33 \%$ tinham idade acima dos 40 anos, $56,66 \%$ tinham o ensino médio completo, $51,66 \%$ possuíam no máximo 5 anos de trabalho na função, foi notado ainda que apenas 14,99\% passaram por curso em BPF ou treinamento no espaço de um ano desde que foram contratados. Após o curso, verificou-se que das 20 questões condizentes às BPF, em 15 delas houve aumento de acertos, corroborando assim a importância da capacitação para manipuladores de alimentos pautadas nas legislações vigentes e nos potenciais efeitos positivos.
\end{abstract}

Palavras-chave: Boas práticas de fabricação; Manipuladores de alimentos; Segurança dos alimentos.

\begin{abstract}
The Food and Nutrition Units (UANs) are responsible for the production of meals, whose objective is to meet the nutritional demands of individuals. Within these units, there has been an increase in the number of foodborne diseases (DTAs), requiring greater care in food handling at these sites. In this context, employees working in this field become potential tools in the transmission of these diseases through their own food. Due to this problem, ANVISA issued RDC $\mathrm{n}^{\circ}$ 216/04 that recommends periodic training in Good Manufacturing Practices. Therefore, this study aimed to evaluate the impact of a GMP course for food handlers in schools and day care centers. The course was held in the municipality of Picuí-PB, and all food handlers of the municipal public network were considered. Questionnaires of sociodemographic and BPH profiles with a special focus on hygiene were applied in two moments, one before and one after the course. After completing the course, it was verified that $88.33 \%$ were female, $43.33 \%$ were over 40 years old, $56.66 \%$ had completed high school, $51.66 \%$ had a maximum of 5 years of work in function, it was also noted that only $14.99 \%$ went through a course in BPF or training in the space of one year since they were hired. After the course, it was verified that of the 20 questions corresponding to the GMP, in 15 of them there was an increase of correct answers, thus corroborating the importance of the qualification for food manipulators based on the current legislation and the potential positive effects.
\end{abstract}

Keywords: Good manufacturing practices; Food handlers; Food safety. 


\section{Resumen}

Las Unidades de Alimentación y Nutrición (UAN) son las encargadas de la elaboración de las comidas, cuyo objetivo es satisfacer las demandas nutricionales de las personas. Dentro de estas unidades, ha habido un aumento en el número de enfermedades transmitidas por alimentos (DTA), que requieren mayor cuidado en la manipulación de alimentos en estos sitios. En este contexto, los empleados que trabajan en este campo se convierten en herramientas potenciales en la transmisión de estas enfermedades a través de su propia alimentación. Debido a este problema, ANVISA emitió el $\mathrm{RDC} \mathrm{n}^{\circ}$ 216/04 que recomienda capacitaciones periódicas en Buenas Prácticas de Manufactura. Por lo tanto, este estudio tuvo como objetivo evaluar el impacto de un curso de BPM para manipuladores de alimentos en escuelas y guarderías. El curso se realizó en el municipio de Picuí-PB, y se consideraron todos los manipuladores de alimentos de la red pública municipal. Se aplicaron cuestionarios de perfiles sociodemográficos y de HBP con especial foco en la higiene en dos momentos, uno antes y otro después del curso. Luego de finalizar el curso, se verificó que $88.33 \%$ eran mujeres, $43.33 \%$ tenían más de 40 años, $56.66 \%$ habían completado el bachillerato, 51.66\% tenían un máximo de 5 años de trabajo en función, también se observó que solo 14.99\% Pasaron por un curso en BPF o capacitación en el espacio de un año desde que fueron contratados. Tras el curso, se comprobó que de las 20 preguntas correspondientes a las BPM, en 15 de ellas hubo un incremento de respuestas correctas, corroborando así la importancia de la calificación para manipuladores de alimentos en base a la legislación vigente y los potenciales efectos positivos.

Palabras clave: Buenas prácticas de fabricación; Manipuladores de alimentos; Seguridad alimenticia.

\section{Introdução}

O fornecimento de uma alimentação de qualidade tem como objetivo a promoção da saúde e a prevenção de doenças, caracterizando assim uma refeição com base em alimentos seguros. O alimento seguro é aquele que não causa doença no comensal. A contaminação através de alimentos é uma preocupação constante em todo mundo, e infelizmente, na maioria dos casos, não é possível identificar um alimento contaminado a olho nu (MORAES, 2018). As doenças transmitidas através dos alimentos são conhecidas como DTAs - Doenças Transmitidas por Alimentos (Abreu, 2013). Essas DTAs podem ser ocasionadas por perigos químicos, físicos e biológicos. De acordo com o Ministério da Saúde, de 2000 a 2017, 12.503 surtos foram notificados, sendo os principais agentes etiológicos a Salmonella, Escherichia coli e o Staphylococcus aureus (Brasil, 2018).

A alimentação coletiva é fornecida dentro das Unidades de Alimentação e Nutrição (UAN), que podem ser localizadas dentro de escolas, universidades, empresas, caracterizando-se assim como unidades institucionais. Além disso, também entram nesse mesmo conceito, os restaurantes, hotéis, hospitais, comissárias ou caterings, bem como toda e qualquer unidade produtora de refeições coletivas (Abreu, 2013).

Uma UAN necessita contar com um quadro de funcionários capacitados para execução das tarefas desenvolvidas no ambiente de trabalho e o consequente alcance dos objetivos da empresa. Quase sempre a contratação de profissionais cabe ao nutricionista, e diante disso, é essencial que o mesmo possua critérios de escolha adequados para a seleção dos melhores profissionais do mercado. Entretanto, na maioria dos casos, no momento da contratação dos servidores, a falta de experiência e principalmente de qualificação, podem comprometer a formação de toda a equipe e desempenho (Teixeira, 2010).

Nesse cenário, surgem as BPF - Boas Práticas de Fabricação, um conjunto de normas operacionais para garantir a produção de alimentos sanitariamente adequadas. O sucesso das BPF se dá por meio de avaliações constantes, bem como inspeções visando a minimização dos riscos dentro do ambiente de produção e manipuladores de alimentos (Souza, 2006). Diante da obrigatoriedade de UANs contarem em seus quadros técnicos com um nutricionista, e da garantia da saúde do consumidor, outros assuntos importantes são notados, tais como: compras; recebimento; armazenamento; descongelamento; reidratação; prépreparo; cocção; resfriamento; porcionamento; reaquecimento; distribuição; higiene dos equipamentos de higiene pessoal do manipulador (Abreu, 2013). Além de proteger a saúde dos comensais, as BPF têm portado papel imprescindível na manutenção de ambientes de trabalho mais organizados, eficientes e com consequente risco de acidentes de trabalho diminuídos. Esse conceito está em vigor há mais de 40 anos, e ainda sim, muitas empresas relutam na implementação das mesmas dentro de suas unidades (Tondo \& Bartz, 2014). 
O Programa de Boas Práticas de Fabricação é um conjunto de normas e regras que visam estabelecer um padrão higiênico-sanitário e padroniza procedimentos e para o desenvolvimento da qualidade em produtos e serviços, atendendo dessa forma, aos padrões nacionais e internacionais já preconizados (Brasil, 2004; dos Santos Ferreira et al., 2013).

No Brasil, existe uma legislação especial voltada para as BPF, a RDC nº 216 da Agência Nacional da Vigilância Sanitária (ANVISA), de 15 de setembro de 2004, que estabelece que as unidades produtoras de alimentos adotem o Manual de Boas Práticas (MBP), os Procedimentos Operacionais Padronizados (POP), e as capacitações em BPF (Brasil, 2004).

Para a implementação das BPF dentro do setor de nutrição e dietética, é necessário a aplicação de uma lista de verificação, que irá mostrar as conformidades e não conformidades encontradas no ambiente, que por conseguinte, o responsável técnico deverá elaborar medidas corretivas para solucionar todas as imperfeições visualizadas, para que se atinja um nível de qualidade higiênico-sanitária nas refeições produzidas dentro da UAN, além disso, o responsável técnico deve capacitar os manipuladores (Brasil, 2004). A Lei estadual n 7.587 de 02 de junho de 2004, estabelece a capacitação obrigatória no estado da Paraíba para manipuladores de alimentos através da Lei da Qualidade Alimentar (Paraíba, 2004). No estado de São Paulo, também existe uma legislação específica, a Portaria CVS no 6 de 10 de março de 1999 (São Paulo, 1999).

É importante capacitar os manipuladores de alimentos em BPF, obedecendo as legislações estaduais e nacional, justificando assim a análise do nível de conhecimento desses profissionais que produzem as refeições que chegam até aos comensais. Sendo assim, o presente estudo tem o objetivo de avaliar o impacto de uma capacitação em Boas Práticas de Manipulação de Alimentos (BPMA) voltada aos manipuladores de alimentos de escolas e creches públicas municipais. A pesquisa também tem o intuito de conhecer o perfil sociodemográfico de manipuladores de alimentos através da investigação do nível de conhecimentos dos manipuladores de alimentos em BPMA por meio de questionários para verificar o nível de conformidade do conhecimento dos manipuladores em relação a RDC nº 216/04 da ANVISA.

\section{Metodologia}

Trata-se de um estudo transversal de abordagem observacional e descritiva, cuja coleta dos dados foi realizada através de questionários elaborados pelo próprio autor aplicados com manipuladores de alimentos antes e após a realização de um curso de Boas Práticas de Fabricação. Esse estudo se deu no município de Picuí-PB, na sede da Secretaria Municipal de Educação da cidade, localizada no interior do estado da Paraíba, na mesorregião da Borborema, há 244km da capital João Pessoa (IBGE, 2018).

O acesso para a realização de algum feito se dá através de métodos e quando se tem a trajetória, torna-se mais viável realizar trajetos conhecendo lugares onde se quer chegar e como fazê-lo. O presente estudo utilizou métodos qualitativos que é importante para o esclarecimento do assunto pesquisado. Nesta pesquisa a coleta de dados ocorreu por meio de entrevistas com questões abertas (Pereira et al. 2018).

Participaram do curso de capacitação em Boas Práticas 60 merendeiras convocadas pela Secretaria Municipal de Educação do município de Picuí, que atuam na manipulação de alimentos na rede pública municipal da zona urbana e rural do município.

Foi realizada uma parceria entre a Universidade Federal de Campina Grande - UFCG, campus Cuité e a Secretaria Municipal de Educação do município de Picuí-PB para a realização de um Curso de Boas Práticas para os manipuladores da localidade. Na ocasião, uma professora da UFCG juntamente com seis alunos do curso de bacharelado em Nutrição foram ministrar o curso de BPF em dois dias consecutivos, tendo sido aplicados questionários antes e após a realização do curso para verificar os impactos do mesmo no grupo de merendeiras. No início, foi aplicado um questionário afim de traçar um diagnóstico dos manipuladores de alimentos, tanto no perfil sociodemográfico quanto nos conhecimentos prévios dos mesmos. 
Os questionários foram entregues a cada manipulador antes do início do curso, e aqueles que desejassem, podiam ter a disposição um dos ministrantes do curso para auxiliá-lo, em caso de ser semialfabetizado ou ter dificuldade de leitura. Entretanto, todos os manipuladores tinham habilidade suficiente para ler e responder os questionários, tendo sido solicitado a ajuda dos ministrantes apenas para esclarecer alguns termos, sem prejuízo nas respostas dadas pelos mesmos. O questionário sobre higiene foi composto de vinte questões que tratavam sobre higienização de instalações, equipamentos, alimentos e pessoal.

Os resultados foram comparados com outros resultados encontrados na literatura quando confrontados com questões a respeito do mesmo tema. Em outros casos, os resultados logrados através deste questionário, tiveram sua análise de acordo com a importância do conhecimento do manipulador a respeito daquele tema para manter as BPF efetivas dentro da UAN.

Foram utilizados dois questionários para serem aplicados, um tratando do perfil sociodemográfico dos manipuladores e o outro relacionado aos conhecimentos em BPF de alimentos com perguntas elaboradas de acordo com a ementa do curso ministrado. Para serem aplicados, foi disponibilizado aos participantes um Termo de Consentimento Livre e Esclarecido - TCLE. Para tabular os dados colhidos na pesquisa, foi utilizado o programa Excel 2016, da Microsoft.

Para avaliar o nível de conhecimento dos manipuladores de alimentos, foi utilizada a metodologia de classificação por grupos segundo de Freitas Saccol et al.(2012), que define o nível de aprendizagem da seguinte ordenação: Grupo 1 - excelente, com $91 \%$ a $100 \%$ de atendimento aos itens; Grupo 2 - bom, com 70\% a 90\%; Grupo 3 - regular, com 50\% a 69\%; Grupo 4 ruim, com 20\% a 49\%; e Grupo 5 - péssimo, com 0\% a 19\%.

\section{Resultados e Discussão}

\subsection{Perfil dos participantes}

Dentre todos os participantes, 88,33\% pertenciam ao gênero feminino, enquanto $11,66 \%$ ao gênero masculino. Machado, Pascoal e Dias (2018) encontrou resultados semelhantes em uma capacitação com manipuladores de restaurantes e lanchonetes realizada na cidade de Salvador - BA, em que 92,00\% dos manipuladores pertenciam ao gênero feminino, enquanto 8,00\% eram do gênero masculino. Já Bastos et al. (2018), em uma avaliação de conhecimento em BPF de manipuladores UAN e nutrição off shore, verificou que a maior parte pertencia ao sexo masculino, com a expressiva quantidade de $95,8 \%$ do sexo masculino, enquanto $4,2 \%$ eram do sexo feminino.

Essa elevada porcentagem masculina deve-se ao fato de haver uma maior prevalência desse gênero no âmbito do off shore. Da Silva Júnior e Ferreira (2007), em uma escala para avaliação de estressores ambientais no contexto do off shore, identificou 92\% pertencentes ao gênero masculino. No entanto, Góios et al. (2017), em um estudo na cidade do Porto, em Portugal, avaliando o nível de conhecimento de manipuladores sobre segurança dos alimentos e alergias, averiguo que $68 \%$ pertenciam ao sexo feminino, enquanto $32 \%$ ao sexo masculino. Percebe-se assim uma prevalência do sexo feminino em UANs, salvo algumas exceções como em serviços de off shore.

Em relação a faixa etária dos participantes, foi notado que não houve a presença de nenhum com idade abaixo dos 20 anos. Verificou-se ainda que 18,33\% dos manipuladores possuíam entre 20 e 29 anos de idade e 38,33\% com 30 a 40 anos de idade. A maior parte dos manipuladores possuíam acima dos 40 anos de idade, com 43,33\%. Ferreira et al. (2013) verificou resultados divergentes em um estudo de conhecimentos, atitudes e práticas em segurança alimentar com manipuladores de hospitais públicos de Salvador-BA, em que 36,7\% tinham até 32 anos, 33,3\% tinham entre 32 a 41 anos e 30\% acima dos 41 anos de idade. Já Devides (2010), em uma análise do perfil socioeconômico de participantes de um programa de BPF em Araraquara - SP, encontrou $20 \%$ dos manipuladores com até 20 anos; $33 \%$ com idade entre 21 e 30 anos; $22 \%$ com idade entre 31 e 40 anos e 25\% com idade superior aos 40 anos. Calvet et al. (2012), avaliando as condições sanitárias de cozinhas de escolas estaduais de São Luís-MA, encontrou uma amostra composta por 86\% dos manipuladores com idade superior aos 40 anos. De 
acordo com Byrd-Bredbernner et al. (2007), os manipuladores sem capacitações em BPF devem ser capacitados para que não venham a tornar-se veículos transmissores de DTA.

No quesito tempo de escolaridade, não foi encontrado nenhum manipulador analfabeto. Achado semelhante ao estudo de Devides (2010), onde um percentual de $20 \%$ dos manipuladores possuía o ensino fundamental incompleto. Da amostra estudada, 6,66\% possuíam o ensino fundamental completo, enquanto que Devides (2010) obteve um resultado de 13\% para esta mesma escolaridade. Ensino médio incompleto foi achado em 3,33\% dos manipuladores, contrastando com Devides (2010) que encontrou 11,5\% neste nível de ensino. O resultado mais expressivo foram os 56,66\% dos manipuladores com o ensino médio completo, corroborado por Devides (2010) que obteve 55\% de manipuladores com mesma escolaridade. Porém, este resultado foi inferior encontrado de Bastos et al. (2018), que relatou 68\% com ensino médio completo. Um quantitativo de $10 \%$ dos manipuladores tinha ensino superior incompleto. $\mathrm{O}$ menor percentual foi $1,66 \%$ dos manipuladores com o ensino superior completo e a mesma porcentagem encontrada com respeito ao nível de pós-graduação. Devides (2010) em seu estudo, constatou que $6 \%$ detinham ensino superior completo.

No que se refere ao tempo de trabalho como manipulador de alimentos, 20\% possuíam menos de 1 ano na função. De 1 a 5 anos, o percentual foi de 31,66\% dos pesquisados, diferentemente de Abadia et al. (2017) que realizou um estudo com merendeiras no município de Rio Branco - AC, tendo 16,7\% o mesmo tempo de atuação. De 6 a 10 anos obteve-se o quantitativo de 23,33\% dos manipuladores. Por fim, 25\% dos manipuladores tinham 11 anos ou mais trabalhando na função, resultado semelhante ao encontrado por Ferreira et al. (2013) que relatou 23,6\% dos manipuladores com mais de 10 anos na função. Abadia et al. (2017) analisando o escore de conhecimento de manipuladores, detectou que o nível foi de 59,12\%, em que ele justifica que um dos prováveis motivos seria o pouco tempo de exercício na função. A falta de conhecimentos em BPF pode gerar atitudes incorretas, provocando risco aos comensais (Oliveira \& Silva, 2009).

Analisando os manipuladores que tiveram capacitações, cursos ou algum tipo de treinamento, verificou-se que 33,33\% nunca passou por algum curso ou passaram por qualquer tipo de treinamento, estando assim em descumprimento com a Lei estadual n 7.587 que preconiza treinamentos a cada dois anos (Paraíba, 2004). Aqueles que tiveram capacitação há mais de um ano, representavam 51,66\% dos participantes. Aqueles que tiveram treinamento entre seis meses à um ano, somavam 3,33\%. E os manipuladores que passaram por algum tipo de treinamento ou curso há seis meses ou menos, equivaliam à 11,66\%. A média de acertos após a capacitação entre aqueles que passaram por algum tipo de treinamento em até um ano e aqueles que nunca passaram ou fizeram há mais de um ano, foi de $66,66 \%$ e 61,83\% respectivamente. O que ressalta mais uma vez a importância de haver frequência e continuidade nas capacitações de BPF.

O montante total dos manipuladores que tiveram algum treinamento foi de $66,67 \%$, resultado bem inferior ao encontrado por Ferreira et al. (2013), que relatou 92,8\% dos pesquisados com algum tipo de capacitação já realizada. Abadia et al. (2017) relatou que 73,3\% não tinha passado por treinamento. Machado, Pascoal e Dias (2018) percebeu que 64\% dos seus entrevistados já haviam passado por algum treinamento. A RDC n 216/2004 da ANVISA, preconiza que os manipuladores de alimentos devem passar por capacitações periodicamente, sendo comprovadas por meio de documentação (Brasil, 2004).

No estado da Paraíba, existe também a Lei estadual nº 7.587 de 2 de junho de 2004 que torna obrigatória a capacitação de manipuladores de nível fundamental e médio através de um Curso Básico de Manipulação de Alimentos (Paraíba, 2004). Diante disso, nota-se que o percentual daqueles que ainda não foram capacitados ainda é bastante significativo, representando aproximadamente um terço dos participantes. De acordo com Trigo (1999), todos os manipuladores devem ser submetidos a capacitações periódicas visando a diminuição do risco de ocorrências de DTA no âmbito da UAN. 


\subsection{Questionário sobre Higiene}

A primeira questão sobre higiene indagava os manipuladores a respeito das duas etapas importantes de higienização de instalações de equipamentos. A alternativa correta era a correspondente a letra $b$, que falava sobre limpeza e desinfecção. Os resultados constam na Tabela 1. Na primeira aplicação, 6,66\% não souberam ou não responderam; 31,66\% erraram e 61,66\% acertaram a questão. Na segunda aplicação, o número daqueles que não souberam ou não responderam diminuiu para 3,33\%; o número de erros também diminuiu para 18,33\%. Já a quantidade de acertos foi bem maior, representando 78,33\%. Góios et al. (2017), avaliando o conhecimento dos manipuladores de alimentos em segurança de alimentos na cidade de Porto, em Portugal, questionando sobre limpeza, encontrou 70,1\% de acertos, percentual semelhante ao achado neste estudo.

Tabela 1 - Questão 1: As duas etapas importantes da higienização de instalações de equipamentos são:

\begin{tabular}{llll}
\hline Resultado & & Antes (\%) & Depois (\%) \\
\cline { 3 - 3 } Acertos & & $37(61,66 \%)$ & $47(78,33 \%)$ \\
Erros & & $19(31,66 \%)$ & $11(18,33 \%)$ \\
$\begin{array}{l}\text { Não Souberam } \\
\text { Responderam }\end{array}$ & Ou Não & $4(6,66 \%)$ & $2(3,33 \%)$ \\
\end{tabular}

Fonte: Autores (2018).

A segunda questão inquiria aos manipuladores sobre o processo de desinfecção do ambiente. Os resultados constam na Tabela 2. Na aplicação realizada antes a ministração do curso, 6,66\% não souberam ou não responderam; 68,33\% erraram a questão enquanto apenas 25,00\% conseguiram assinalar corretamente. Após a ministração do curso, nenhum manipulador ficou sem responder a questão; o número de erros diminuiu para 48,33\%. No tocante as assertivas corretas, o percentual aumentou de $25,00 \%$ para $51,66 \%$, representando um ganho de mais de $100 \%$.

De Souza et al. (2015) avaliando condições higiênico-sanitárias de manipuladores de alimentos de rua, verificou que apenas $10 \%$ deles realizavam a desinfecção de maneira adequada. Segundo o Manual de Práticas de Elaboração e Serviços de Refeições para Coletividades da Associação Brasileira de Refeições Coletivas (2015), a desinfecção deve ser realizada com água corrente, em seguida com detergente neutro e finalmente com solução clorada 200 ppm ou álcool a $70 \%$.

Tabela 2 - Questão 2: A desinfecção só será eficiente quando:

\begin{tabular}{|c|c|c|c|}
\hline Resultado & & Antes (\%) & Depois (\%) \\
\hline Acertos & & $15(25,00 \%)$ & $31(51,66 \%)$ \\
\hline Erros & & $41(68,33 \%)$ & $29(48,33 \%)$ \\
\hline $\begin{array}{l}\text { Não Souberam } \\
\text { Responderam }\end{array}$ & Ou Não & $4(6,66 \%)$ & $0(0,00 \%)$ \\
\hline
\end{tabular}

Fonte: Autores (2018).

A terceira pergunta questionou os manipuladores a respeito da função do detergente. Os resultados antes e após a aplicação do questionário estão na Tabela 3. Na primeira aplicação, aqueles que não souberam ou não responderam representavam 11,66\%; quanto aos que erraram, o percentual foi de 18,33\%; já aqueles que acertaram, representavam $70,00 \%$. Na segunda aplicação, ninguém deixou de responder a questão, porém o número dos que erraram dobrou, totalizando 36,66\%, consequentemente o número dos que acertaram diminuiu levemente para 63,33\%. 
É provável que o fato de ter diminuído o número de acertos tenha sido pela desatenção de alguns manipuladores ou ainda pelo assunto sobre detergentes não ter sido abordado corretamente em alguma das turmas, repercutindo na confusão de ideias de alguns entrevistados. É necessário que o manipulador entenda a importância e função de um detergente dentro de um serviço de nutrição, para que ele possa realizar suas atividades de maneira adequada, Carvalho et al. (2017), realizando uma proposta de reestruturação física de uma UAN militar, identificou através de uma lista de verificação de boas práticas com 68 itens, que apenas $33,00 \%$ estavam em conformidade em relação ao detergente.

Tabela 3 - Questão 3: Qual a função de um detergente?

\begin{tabular}{lcll}
\hline Resultado & & Antes (\%) & Depois (\%) \\
\cline { 3 - 4 } Acertos & & $42(70,00 \%)$ & $38(63,33 \%)$ \\
Erros & & $11(18,33 \%)$ & $22(36,66 \%)$ \\
Não Souberam & Ou Não & $7(11,66 \%)$ & $0(0,00 \%)$ \\
Responderam & & & \\
\hline
\end{tabular}

Fonte: Autores (2018).

A quarta questão indaga sobre o desinfetante mais utilizado na higienização de cozinhas. Os resultados obtidos constam na Tabela 4. Na primeira aplicação, 3,33\% não souberam ou não responderam; $25,00 \%$ erraram a questão enquanto $71,66 \%$ assinalaram corretamente. Em estudo semelhante, Devides (2010) questionando manipuladores participantes de um programa de capacitação de BPF do município de Araraquara - SP a respeito da solução clorada, obteve na avaliação diagnóstica um percentual de 47,00\% de acertos. Na segunda aplicação 5,00\% não souberam ou não responderam; o número daqueles que erraram diminuiu para $15,00 \%$ e o número de acertos foi de $80,00 \%$. Devides (2010) obteve na avaliação final um percentual de $82,00 \%$.

Tabela 4 - Questão 4: O produto desinfetante mais utilizado na higienização de cozinhas é:

\begin{tabular}{llll}
\hline Resultado & & Antes (\%) & Depois (\%) \\
\cline { 2 - 3 } Acertos & & $43(71,66 \%)$ & $48(80,00 \%)$ \\
Erros & $15(25,00 \%)$ & $9(15,00 \%)$ \\
Não Souberam \\
Responderam
\end{tabular}

Fonte: Autores (2018).

A quinta pergunta questionou a respeito da utilização de produtos com odor em áreas de alimentos. Os resultados constam na Tabela 5. Na primeira aplicação, 1,66\% dos manipuladores não souberam ou não responderam; nenhum manipulador errou a questão e 98,33\% acertaram a questão. Na segunda avaliação, o percentual dos que não souberam ou não responderam permaneceu em 1,66\%. Porém, quanto aqueles que erraram, dessa vez, 3,33\% assinalou incorretamente a questão; já o número daqueles que acertaram teve um decréscimo de 3,33\%, ficando com 95,00\% no total. Mais uma vez supõem-se que tenha havido a ausência de abordagem de conteúdo em uma das turmas. Não foram encontrados outros estudos na literatura com relação ao uso de produtos com odor em área de alimentos. 
Tabela 5 - Questão 5: Por que não se devem usar produtos com odor em áreas de manipulação de alimentos?

\begin{tabular}{|c|c|c|c|c|}
\hline Resultado & & & Antes (\%) & Depois (\%) \\
\hline Acertos & & & $59(98,33 \%)$ & $57(95,00 \%)$ \\
\hline Erros & & & $0(0,00 \%)$ & $2(3,33 \%)$ \\
\hline $\begin{array}{l}\text { Não Souberam } \\
\text { Responderam }\end{array}$ & $\mathrm{Ou}$ & Não & $1(1,66 \%)$ & $1(1,66 \%)$ \\
\hline
\end{tabular}

Fonte: Autores (2018).

Na sexta pergunta, os manipuladores foram questionados acerca das atividades de preparo dos alimentos. Os resultados constam na Tabela 6. Na primeira aplicação, 11,66\% não souberam ou não responderam; 28,33\% erraram a questão, sendo assim, 60,00\% acabaram acertando a pergunta. Na segunda aplicação, 5,00\% não souberam ou não responderam; 25,00\% terminaram errando. Diante disso, a quantidade de manipuladores que acertaram a questão aumentou para 70,00\%, chegando assim, a um resultado satisfatório. Não foram encontrados estudos na literatura com relação a questão de número 6 do questionário de higiene.

Tabela 6 - Questão 6: Durante as atividades de preparo dos alimentos, não é recomendado:

\begin{tabular}{lccc}
\hline Resultado & Antes (\%) & Depois (\%) \\
\cline { 3 - 4 } Acertos & & $36(60,00 \%)$ & $42(70,00 \%)$ \\
Erros & $17(28,33 \%)$ & $15(25,00 \%)$ \\
$\begin{array}{l}\text { Não Souberam } \\
\text { Responderam }\end{array}$ & & Não & $7(11,66 \%)$ \\
\hline
\end{tabular}

Fonte: Autor (2018).

Na sétima questão, indagava-se sobre qual era a frequência que os coletores de lixo deveriam ser higienizados. Os resultados constam na Tabela 7. Na primeira aplicação, 1,66\% não soube ou não respondeu; 3,33\% responderam de maneira errada enquanto $95,00 \%$ acertaram a questão. Após a segunda aplicação, o número daqueles que não souberam ou não responderam aumentou para 5,00\%. Já o percentual dos que erraram a questão diminuiu de 3,33\% para 1,66\%.

Quanto aos que assinalaram corretamente, o percentual sofreu uma ligeira queda de 95,00\% para 93,33\%. Os resultados na Tabela 7 mostram que pode ser provável que após a ministração do curso, 3,33\% dos manipuladores que tinham acertado a questão na primeira aplicação tenham ficado em dúvida e deixado de responder a pergunta. Cardoso et al. (2010) em um estudo com 235 escolas públicas de Salvador - BA, verificou que em 60,9\% delas a lixeira não eram bem higienizadas.

Tabela 7 - Questão 7: Com que frequência devem ser higienizados os coletores de lixo?

\begin{tabular}{llll}
\hline Resultado & & Antes (\%) & Depois (\%) \\
\cline { 3 - 3 } Acertos & & $57(95,00 \%)$ & $56(93,33 \%)$ \\
Erros & $2(3,33 \%)$ & $1(1,66 \%)$ \\
Não Souberam & Ou Não & $1(1,66 \%)$ & $3(5,00 \%)$ \\
Responderam & & & \\
\hline
\end{tabular}


A oitava questão indagava a respeito da higienização das caixas de gordura. Os resultados estão na Tabela 8. Na primeira aplicação, $15,00 \%$ não souberam ou não responderam; 68,33\% erraram a questão e 16,66\% assinalaram corretamente. Na segunda aplicação, o percentual dos que não souberam ou não responderam diminuiu para 1,66\%. O percentual dos que assinalaram a questão erroneamente representou 91,66\%. Nesse caso, há um aumento dos erros em relação a primeira aplicação, o que pode ter sido ocasionado pela falha na abordagem de higienização de instalações e equipamentos em alguma turma, resultando neste aumento. Messias (2007) encontrou 100,00\% de adequação quanto ao descarte de gorduras em lanchonetes fast food.

Tabela 8 - Questão 8: As caixas de gordura devem ser higienizadas preferencialmente:

\begin{tabular}{lccc}
\hline Resultado & Antes (\%) & Depois (\%) \\
\cline { 3 - 4 } Acertos & & $10(16,66 \%)$ & $4(6,66 \%)$ \\
Erros & & $41(68,33 \%)$ & $55(91,66 \%)$ \\
$\begin{array}{l}\text { Não Souberam } \\
\text { Responderam }\end{array}$ & Ou Não & $9(15,00 \%)$ & $1(1,66 \%)$ \\
\hline
\end{tabular}

Fonte: Autor (2018).

Na nona questão, foi indagado aos manipuladores sobre a higienização de portas e janelas. Os resultados estão descritos na Tabela 9. Na primeira aplicação, 1,66\% não soube ou não respondeu; 28,33\% erraram a questão enquanto 70,00\% assinalaram corretamente. Após a segunda aplicação, o percentual quanto aqueles que não souberam ou não responderam permaneceu igual, com $1,66 \%$. Aqueles que erraram decaíram para 23,33\%. Os que acertaram a questão representavam 75,00\%, tendo tido um aumento de 5,00\% em relação a primeira aplicação. Esse resultado ainda é um pouco inferior ao encontrado por Messias (2007), que avaliando aspectos higiênico-sanitários de lanchonetes fast food, verificou que 91,7\% dos manipuladores mantinham as portas higienizadas conforme o preconizado pela ANVISA na RDC n²16/2004 (Brasil, 2004).

Tabela 9 - Questão 9: Os trincos e maçanetas de portas e janelas devem ser higienizados:

\begin{tabular}{llll}
\hline Resultado & & Antes (\%) & Depois (\%) \\
\cline { 3 - 4 } Acertos & & $42(70,00 \%)$ & $45(75,00 \%)$ \\
Erros & & $17(28,33 \%)$ & $14(23,33 \%)$ \\
$\begin{array}{l}\text { Não Souberam } \\
\text { Responderam }\end{array}$ & Ou Não & $1(1,66 \%)$ & $1(1,66 \%)$ \\
\hline
\end{tabular}

Fonte: Autor (2018).

Na décima questão, foi perguntado a respeito da higienização das telas milimétricas de janelas e portas. Os resultados constam na Tabela 10. Na primeira aplicação, 3,33\% não souberam ou não responderam. O percentual dos que erraram a questão foi bastante elevado, representando $81,66 \%$, enquanto os que acertaram foi de $15,00 \%$. Na segunda aplicação, o número dos que não souberam ou não responderam aumentou para 5,00\%. Entretanto, quanto aos que erraram, o percentual foi substancialmente menor, chegando a 65,00\%. Já aqueles que acertaram, a quantidade de manipuladores dobrou de 15,00\% para 30,00\%, o que representa um ganho positivo quanto a essa temática de higienização através do curso de BPF. Oliveira (2008) avaliando as conformidades e não conformidades em uma fábrica de linha de file de peixe antes e após um treinamento em BPF, verificou que haviam $90,00 \%$ de conformidades após o treinamento. 
O resultado foi bem superior ao encontrado neste estudo, entretanto, o que pode ter influenciado foi o nível inicial de adequação que já havia na fábrica de $71,00 \%$, o que representa um ganho de $19,00 \%$. Neste estudo, os resultados foram bem expressivos, o que demonstra 100,00\% de evolução em acertos da questão após o treinamento, ressaltando dessa forma mais uma vez a importância da capacitação em BPF.

Tabela 10 - Questão 10: As telas milimétricas de janelas e portas devem ser higienizadas:

\begin{tabular}{llll}
\hline Resultado & Antes (\%) & Depois (\%) \\
\hline Acertos & $9(15,00 \%)$ & $18(30,00 \%)$ \\
Erros & & $49(81,66 \%)$ & $39(65,00 \%)$ \\
Não Souberam & Ou Não & $2(3,33 \%)$ & $3(5,00 \%)$ \\
Responderam & & & \\
\hline
\end{tabular}

Fonte: Autor (2018).

$\mathrm{Na}$ questão onze, foi perguntado aos manipuladores sobre a lavagem dos carrinhos de transporte e caixas térmicas. Os resultados estão descritos na Tabela 11. Na primeira aplicação, 15,00\% não souberam ou não responderam; 40,00\% assinalaram de maneira errada enquanto 45,00\% acertaram a questão. Oliveira (2008) em um estudo que verificou BPF antes e após treinamento através de check-list, encontrou 78,00\% de conformidades, bem maior que o encontrado neste estudo. Na segunda aplicação, ninguém ficou sem responder a questão; o percentual dos que erraram permaneceu em 40,00\%, enquanto os que acertaram aumentou para 60,00\%. Já Oliveira (2008) encontrou 88,00\% de conformidades para a higiene de equipamentos, móveis e utensílios. Enquanto no estudo de Oliveira (2008) houve um ganho de mais 10,00\% na aprendizagem, neste estudo o ganho foi de $15,00 \%$, sendo ligeiramente maior do que no estudo supracitado. Diante do exposto, percebe-se que a abordagem relacionada a esse tema foi mais efetiva.

Tabela 11 - Questão 11: Carrinhos de transporte e caixas térmicas devem ser lavados:

\begin{tabular}{llll}
\hline Resultado & Antes (\%) & Depois (\%) \\
\cline { 3 - 4 } Acertos & $27(45,00 \%)$ & $36(60,00 \%)$ \\
Erros & $24(40,00 \%)$ & $24(40,00 \%)$ \\
Não Souberam \\
Responderam
\end{tabular}

Fonte: Autor (2018).

A questão 12 indagava sobre as características de um bom desinfetante. Os resultados estão descritos na Tabela 12. Na primeira aplicação, 6,66\% não souberam ou não responderam. Um quantitativo de 83,33\% assinalou de maneira errônea, enquanto apenas 10,00\% acertaram a questão. Na segunda aplicação, ninguém ficou sem responder à pergunta. Quanto aos que erraram, o percentual diminuiu para 76,66\% ao passo que 23,33\% acertaram a questão, o que representa um aumento de mais de 100\% em relação a primeira aplicação. Munhoz (2007) em uma avalição do conhecimento de BPF em rede municipal de ensino em Botucatu - SP, não identificou microrganismos patógenos nos alimentos servidos, o que entre outras coisas, atribuiu ao fato do uso de detergentes e da aplicação da RDC n ${ }^{\circ}$ 216/2004 (BRASIL, 2004). Diante disso, entender a importância da correta utilização de desinfetantes e detergentes nos procedimentos de limpeza da UAN é imprescindível para manutenção da saúde dos manipuladores e dos comensais. 
Tabela 12 - Questão 12: Quais são as características de um bom desinfetante?

\begin{tabular}{|c|c|c|c|c|}
\hline Resultado & & & Antes (\%) & Depois (\%) \\
\hline Acertos & & & $6(10,00 \%)$ & $14(23,33 \%)$ \\
\hline Erros & & & $50(83,33 \%)$ & $46(76,66 \%)$ \\
\hline $\begin{array}{l}\text { Não Souberam } \\
\text { Responderam }\end{array}$ & $\mathrm{Ou}$ & Não & $4(6,66 \%)$ & $0(0,00 \%)$ \\
\hline
\end{tabular}

Fonte: Autor (2018).

Na décima terceira questão, indagou-se a respeito da higienização de equipamentos de manutenção fria. Os resultados constam na Tabela 13. Na primeira aplicação, ninguém ficou sem responder a questão. Os manipuladores que erraram representaram $23,33 \%$ à medida que $76,66 \%$ assinalaram corretamente a questão. Na segunda aplicação, semelhantemente a primeira, ninguém ficou sem responder a questão.

O percentual dos manipuladores que erraram a questão diminuiu para 10,00\% ao mesmo tempo que $90,00 \%$ assinalaram corretamente a questão, representando um considerável aumento de acertos. Esse resultado supera o resultado encontrado por Messias (2007), que apen 41,7\% dos manipuladores de fast food realizavam a higienização com frequência adequada. Com isso, a capacitação em BPF pode melhorar consideravelmente esse quadro.

Tabela 13 - Questão 13: A higienização de equipamentos de manutenção fria como geladeira, câmaras e freezers, devem ser feitas:

\begin{tabular}{llll}
\hline Resultado & Antes (\%) & Depois (\%) \\
\cline { 3 - 3 } Acertos & & $46(76,66 \%)$ & $54(90,00 \%)$ \\
Erros & & $14(23,33 \%)$ & $6(10,00 \%)$ \\
Não Souberam & Ou Não & $0(0,00 \%)$ & $0(0,00 \%)$ \\
Responderam & & & \\
\hline
\end{tabular}

Fonte: Autor (2018).

A décima quarta questão indagava sobre o ensacamento de talheres com sacos plásticos. Os resultados estão na Tabela 14. Na primeira aplicação, 6,66\% não souberam ou não responderam. Os manipuladores que erraram a questão representaram $50,00 \%$ ao passo que 43,33\% acertaram a pergunta. Na segunda aplicação, 1,66\% não soube ou não respondeu. Quanto aos que erraram, o percentual diminuiu para 30,00\% à medida que os que acertaram aumentou de 43,33\% para 68,33\%. Leles, Pinto e Tórtora (2005), investigando a contaminação microbiana de talheres em restaurantes self-service, verificou que 41,5\% dos garfos e 35,4\% das facas apresentavam contaminação superior a $10^{2} \mathrm{UFC} / \mathrm{cm}^{2}$, o que segundo os autores, é um nível de risco bem elevado aos comensais. Nesse sentido, é essencial preservar higienicamente os talheres para que cheguem aos comensais sem risco bacteriológico. 
Tabela 14 - Questão 14: Quando se faz uso de sacos individualizados para ensacar talheres, o que é recomendado?

\begin{tabular}{|c|c|c|c|c|}
\hline Resultado & & & Antes (\%) & Depois (\%) \\
\hline Acertos & & & $26(43,33 \%)$ & $41(68,33 \%)$ \\
\hline Erros & & & $30(50,00 \%)$ & $18(30,00 \%)$ \\
\hline $\begin{array}{l}\text { Não Souberam } \\
\text { Responderam }\end{array}$ & $\mathrm{Ou}$ & Não & $4(6,66 \%)$ & $1(1,66 \%)$ \\
\hline
\end{tabular}

Fonte: Autor (2018).

A décima quinta questão tratava a respeito da gradação do álcool. Os resultados constam na Tabela 15. Na primeira aplicação, 1,66\% não soube ou não respondeu. Quanto aos que assinalaram incorretamente, o resultado foi de 20,00\% à medida que 78,33\% acertaram a questão. Na segunda aplicação, ninguém ficou sem responder. Apenas 1,66\% erraram a questão ao passo que 98,33\% acertaram. Oliveira et al. (2015) destacou a importância do uso de álcool 70\% como sanitizante e potencial destruidor de micro-organismos.

Tabela 15 - Questão 15: O álcool para uso em desinfecção deve ter uma gradação de:

\begin{tabular}{|c|c|c|c|}
\hline Resultado & & Antes (\%) & Depois (\%) \\
\hline Acertos & & $47(78,33 \%)$ & $59(98,33 \%)$ \\
\hline Erros & & $12(20,00 \%)$ & $1(1,66 \%)$ \\
\hline $\begin{array}{l}\text { Não Souberam } \\
\text { Responderam }\end{array}$ & Ou Não & $1(1,66 \%)$ & $0(0,00 \%)$ \\
\hline
\end{tabular}

Fonte: Autor (2018).

A décima sexta questão versava sobre a higienização dos alimentos com produtos caseiros na ausência de produtos profissionais. Os resultados estão descritos na Tabela 16. Na primeira aplicação, ninguém ficou sem responder a questão. Os que erraram representaram 5,00\% ao passo que 95,00\% acertaram a pergunta. Na segunda aplicação, de igual modo à primeira, ninguém ficou sem responder. Apenas 3,33\% erraram a questão, em contrapartida, 96,66\% acertaram, representando um ligeiro aumento em relação a aplicação anterior a ministração do curso. Não foi encontrado na literatura, até o presente momento, estudos com questões idênticas com manipuladores de alimentos, entretanto, Silva et al. (2017), avaliando condições higiênicas de cachorros-quentes no cinturão turístico de Natal-RN, verificou que apenas 6,00\% dos manipuladores faziam uso de álcool $70 \%$ como alternativa de limpeza. Silva et al. (2017), ainda enfatiza em seu estudo a importância de seguir as recomendações do Ministério da Saúde quanto ao uso do álcool $70 \%$ para antissepsia das mãos. 
Tabela 16 - Questão 16: Na falta de produtos profissionais para desinfetar alimentos, que produto caseiro à base de cloro podemos usar?

\begin{tabular}{llll}
\hline Resultado & & Antes (\%) & Depois (\%) \\
\cline { 3 - 4 } Acertos & & $57(95,00 \%)$ & $58(96,66 \%)$ \\
Erros & & $3(5,00 \%)$ & $2(3,33 \%)$ \\
Não Souberam & Ou Não & $0(0,00 \%)$ & $0(0,00 \%)$ \\
Responderam & & & \\
\hline
\end{tabular}

Fonte: Autor (2018).

Na décima sétima questão, foi tratado a respeito de buchas e esponjas. Os resultados estão descritos na Tabela 17. Na primeira aplicação, 3,33\% não souberam ou não responderam. Quanto aqueles que erraram a questão, representavam 13,33\% à medida que $83,33 \%$ assinalaram corretamente. Na segunda aplicação, ninguém ficou sem responder. O percentual dos que erraram caiu para 11,66\% ao passo que aqueles que acertaram representaram 88,33\%. Esse resultado é inferior ao encontrado por Messias (2007), que encontrou 100,00\% de conformidades na disponibilidade e adequação das esponjas. Simon e Benedetti (2016), avaliando a contaminação de buchas e esponjas de serviços de alimentação na cidade de Marmeleiro - PR, concluiu que $77,77 \%$ das esponjas eram contaminadas com coliformes fecais, o que traz à tona a importância e necessidade de higienizá-las diariamente.

Tabela 17 - Questão 17: Buchas e esponjas devem ser higienizadas diariamente como qualquer utensílio e devem ser guardadas em local:

\begin{tabular}{llll}
\hline Resultado & & Antes (\%) & Depois (\%) \\
\cline { 3 - 4 } Acertos & & $50(83,33 \%)$ & $53(88,33 \%)$ \\
Erros & $8(13,33 \%)$ & $7(11,66 \%)$ \\
Não Souberam & Ou Não & $2(3,33 \%)$ & $0(0,00 \%)$ \\
Responderam & & & \\
\hline
\end{tabular}

Fonte: Autor (2018).

Na décima oitava questão, foi perguntado a respeito da desinfecção de tábuas de corte de carnes e sua higienização. Os resultados constam na Tabela 18. Na primeira aplicação, os que não souberam ou não responderam representaram 1,66\%. Aqueles que assinalaram incorretamente a questão configuraram 76,66\% à medida que 21,66\% acertaram. Na segunda aplicação, ninguém ficou sem responder. Os que erraram a questão diminuíram bastante, chegando ao percentual de $26,66 \%$ ao passo que 73,33\% assinalaram corretamente a pergunta. Esses resultados expressivos podem ser consequência do enfoque na dinâmica de contaminação cruzada realizada através de tábuas de carnes. Carrasco, Guevara e Falcón (2013), em uma avaliação sobre o impacto de capacitações sanitárias oferecidas por um governo local no distrito de Los Olivos, no município de Lima, no Peru, percebeu que 85,00\% mantêm as tábuas de corte limpas corretamente. 
Tabela 18 - Questão 18: A melhor maneira de desinfetar tábuas de corte é borrifar água clorada depois de limpas e lavadas, deixando o produto agir por:

\begin{tabular}{|c|c|c|c|c|}
\hline Resultado & & & Antes (\%) & Depois (\%) \\
\hline Acertos & & & $13(21,66 \%)$ & $44(73,33 \%)$ \\
\hline Erros & & & $46(76,66 \%)$ & $16(26,66 \%)$ \\
\hline $\begin{array}{l}\text { Não Souberam } \\
\text { Responderam }\end{array}$ & $\mathrm{Ou}$ & Não & $1(1,66 \%)$ & $0(0,00 \%)$ \\
\hline
\end{tabular}

Fonte: Autor (2018).

Na décima nona questão, foi perguntado a respeito de qual resolução da ANVISA tratava sobre BPF. Os resultados estão descritos na Tabela 19. Na primeira aplicação, 36,66\% não souberam ou não responderam, o que representa um percentual elevado em comparação as outras questões. O percentual dos que erraram chegou a 13,33\% à medida que 50,00\% assinalaram corretamente a questão. Morais et al. (2016) realizou uma avaliação com manipuladores de alimentos de mercados públicos de Teresina - PI sobre Boas Práticas, e quando questionados, apenas 15\% responderam corretamente. Na segunda aplicação, ninguém ficou sem responder. Apenas 1,66\% erraram a questão, em contrapartida, 98,33\% acertaram a questão, superando estudo semelhante realizado por Mello e Gama (2010), em que apenas 18,4\% dos manipuladores responderam conhecer as BPF, o que na prática, representa a quase unanimidade no aprendizado sobre o assunto e a sua legislação nacional específica, a RDC n 216/2004 da ANVISA. Stefanello, Linn, \& Mesquita (2009) reforça que o treinamento em boas práticas operacionais é um pré-requisito para se alcançar a inocuidade dos alimentos, já que normalmente a contaminação alimentar está associada a falta de conhecimento ou negligência por parte dos colaboradores.

Tabela 19 - Questão 19: Qual é a resolução da ANVISA que trata do regulamento técnico de Boas Práticas para Serviços de Alimentação?

\begin{tabular}{|c|c|c|c|c|}
\hline Resultado & & & Antes (\%) & Depois (\%) \\
\hline Acertos & & & $30(50,00 \%)$ & $59(98,33 \%)$ \\
\hline Erros & & & $8(13,33 \%)$ & $1(1,66 \%)$ \\
\hline $\begin{array}{l}\text { Não Souberam } \\
\text { Responderam }\end{array}$ & $\mathrm{Ou}$ & Não & $22(36,66 \%)$ & $0(0,00 \%)$ \\
\hline
\end{tabular}

Fonte: Autor (2018).

A vigésima questão, a última do questionário, tratava sobre a higienização de luminárias, interruptores e tomadas. Os resultados estão descritos na Tabela 20. Na primeira aplicação, 3,33\% não souberam ou não responderam. Ninguém assinalou a questão de maneira errada, ao passo que 96,66\% acertaram a pergunta. Na segunda aplicação, ninguém ficou sem responder a questão. Aqueles que erraram, nessa aplicação, representaram 3,33\% à medida que quanto aos que acertaram o percentual permaneceu o mesmo com 96,66\%. Diante do exposto, o resultado é superior ao encontrado por Messias (2007), que apenas 91,7\% dos manipuladores de lanchonetes mantinham e higienizavam corretamente as luminárias. 
Tabela 20 - Questão 20: Quando se realiza a higienização de luminárias, interruptores e tomadas, qual a advertência e recomendações devemos cumprir?

\begin{tabular}{llll}
\hline Resultado & & Antes (\%) & Depois (\%) \\
\hline Acertos & & $58(96,66 \%)$ & $58(96,66 \%)$ \\
Erros & & $0(0,00 \%)$ & $2(3,33 \%)$ \\
Não Souberam & Ou Não & $2(3,33 \%)$ & $0(0,00 \%)$ \\
Responderam & & & \\
\hline
\end{tabular}

Fonte: Autor (2018).

De um modo geral, foi notado que antes do treinado, houve uma média de $59,16 \%$ de acertos entre todos os manipuladores e após o curso, 71,83\% de acertos, o que comprova o impacto positivo de uma capacitação de em BPMA.

\section{Considerações Finais}

Os resultados do questionário sobre BPF após o curso mostram, de acordo com a metodologia usada de Saccol et al. (2012), que das 20 questões, 6 tiveram níveis de resposta excelentes, 7 se enquadraram no nível bom, 4 obtiveram nível regular, 2 tiveram nível ruim e apenas 1 nível péssimo. Portanto, em suma, os resultados foram satisfatórios com a aplicação do curso.

$\mathrm{O}$ impacto de um curso em BPF com manipuladores de alimentos tornou-se positivo. Manipuladores que foram capacitados tendem a conhecer melhor as regras para produzirem alimentos em condições mais salubres. A grande maioria dos manipuladores neste estudo são do sexo feminino, ainda que existam outros ambientes que a maioria seja do sexo masculino, nota-se pelas pesquisas de perfil na área de UAN que de uma maneira geral, a maioria dos manipuladores pertencem ao sexo feminino. Neste estudo, a faixa etária com maior prevalência foi a superior aos 40 anos. Mais da metade dos manipuladores possuíam o ensino médio completo, corroborando o que foi encontrado em outros estudos. Mais da metade dos manipuladores tinham 5 anos ou menos de trabalho na função, o que nos permite perceber que mesmo quase a metade dos manipuladores tendo idade igual ou superior aos 40 anos, o tempo de trabalho na função é menor.

Uma significativa parcela dos manipuladores, 33,33\%, nunca passaram por qualquer tipo de curso, descumprindo assim o que é preconizado na Lei estadual 7.587 de 02 de junho de 2004 (Paraíba, 2004). É notório assim, que mesmo a RDC n²16/2004 já fazendo mais de 14 anos, há ainda uma grande carência em capacitações em BPF. Ainda se analisou de acordo com as más práticas de manipuladores, que podem ocasionar DTAs, que a partir de capacitações em BPF, os riscos podem ser diminuídos, ressaltando mais uma vez o impacto positivo de investimentos na área.

O estudo realizado por Melo et al. (2020), observou que a compressão sobre a importância das BPFs requer a realização de intervenções educacionais de forma contínua e na execução adequada da funcionalidade das ações normativas de vigilância para o combate das DTAs. Eles ainda relatam que a capacitação e a investigação por órgãos competentes apresentam um efeito no aperfeiçoamento do conhecimento e da prática dos funcionários na manutenção das condições sanitárias de seus estabelecimentos.

Manipuladores capacitados tendem a conhecer melhor a RDC n 216/2004 da ANVISA e as BPF, o que não é garantia de sua aplicação na rotina das atividades da manipulação. Apesar disso, ainda são necessários mais estudos na área para avaliar o nível de atitudes e práticas adotadas pelos mesmos quando após uma capacitação mais frequente, para aferir o conhecimento adquirido e/ou redirecionar os conteúdos e metodologias, a fim de se atingir o maior nível de comprometimento com as BPMA. Mais estudos na área de capacitações de BPF são necessários para avaliar outros impactos positivos, como por exemplo, vantagens no momento de empresas contratarem e valor agregado dos produtos produzidos seguindo as legislações vigentes. 
Ainda é necessário melhorar a metodologia, adequando cada vez mais com o público-alvo e sendo realizadas constantes capacitações em outros assuntos com maior profundidade e maior tempo para aplicar metodologias mais dinâmicas possíveis de modo que o conhecimento seja assimilado e posto em prática. Sugere-se para futuras pesquisas, no âmbito das BPFs, o aperfeiçoamento dos questionários utilizados nas intervenções deste estudo para que possa agregar conhecimento científico nessa área que é bem ampla em pontos de pesquisa. Aconselha-se também utilizar mais métodos práticos que envolvam mais o manipulador ouvinte da capacitação, fazendo com que o mesmo consiga compreender de maneira mais fidedigna o assunto abordado nas ações.

A pesquisa demonstrou ainda que a metodologia adotada, de modo geral, foi eficiente na transmissão de conhecimentos para os manipuladores. Entretanto, outros estudos são necessários para avaliar novas metodologias que alcancem resultados cada vez mais precisos que vão ao encontro das necessidades e o contexto da realidade de atuação dos manipuladores.

\section{Referências}

Abreu E. S. D, Spinelli M. G. N, \& Pinto A. M. D. S. (2013). Gestão de unidades de alimentação e nutrição: um modo de fazer. (5a ed.), Metha.

Abadia, L. D. L., Maffi, B. D. A., Lima, S. G., Medeiros, I. M. S., Ramalho, A. A., \& Martins, F. A. (2017). Conhecimento de merendeiros sobre segurança dos alimentos, em pré-escolas atendidas pelo PNAE, no município de Rio Branco-AC. Hig. aliment, 31(264/265), 45-51. https://pesquisa.bvsalud.org/portal/resource/pt/biblio-833024?lang=pt

Associação Brasileira das Empresas de Refeições Coletivas - ABERC. (2015). Manual ABERC de Práticas de Elaboração e Serviço de Refeições para Coletividades. https://www.aberc.com.br/produtosDetail.asp?IDMenu=35\&ID_Cat=19\&ID_Prod=49

Bastos, L. I. A. C., Silva, L. A. A., Santanna, M. S. L., Casaes, R. S. (2018). Avaliação do conhecimento em Boas Práticas de Fabricação de Manipuladores de Unidades de Alimentação e Nutrição. Higiene Alimentar, 32, 282-283. https://docs.bvsalud.org/biblioref/2018/10/916505/282-283-jul-ago-2018-24-29.pdf

Brasil. Ministério da Saúde. Agência Nacional de Vigilância Sanitária. Resolução-RDC nº 216, de 15 de setembro de 2004. Dispõe sobre Regulamento Técnico de Boas Práticas para Serviços de Alimentação. Diário Oficial da União, 16 set. 2004. https://bvsms.saude.gov.br/bvs/saudelegis/anvisa/2004/res0216_15_09_2004.html

Brasil. Ministério da Saúde. Sistema de Vigilância em Saúde. Surtos de Doenças Transmitidas por Alimentos no Brasil. portalarquivos.saude.gov.br/images/pdf/2018/.../Apresenta----o-Surtos-DTA-2018.pdf

Brasil. Resolução RDC ANVISA/MS n. 275, de 21 de outubro de 2002. Regulamento Técnico de Procedimentos Operacionais Padronizados aplicados aos Estabelecimentos Produtores/Industrializadores de Alimentos e a Lista de Verificação das Boas Práticas de Fabricação em Estabelecimentos Produtores/Industrializadores de Alimentos. Diário Oficial da União, Brasília, DF, $06 \quad$ nov. 2002. http://bvsms.saude.gov.br/bvs/saudelegis/anvisa/2002/anexos/anexo_res0275_21_10_2002_rep.pdf

Byrd-Bredbenner, C., Wheatley, V., Schaffner, D., Bruhn, C., Blalock, L., \& Maurer, J. (2007). Development and implementation of a food safety knowledge instrument. Journal of food science education, 6(3), 46-55. https://doi.org/10.1111/j.1541-4329.2007.00029.x

Calvet, R. M., Cordeiro, J. R., Lima, M. D. F. V., Varão, H. C., Muratori, M. C. S., \& Keller, K. M. (2012). Condições de funcionamento das cozinhas de escolas estaduais de São Luís, MA. Hig. alim., 41-44. https://pesquisa.bvsalud.org/portal/resource/pt/vti-12668

Cardoso, R. D. C. V., Góes, J. Â. W., Almeida, R. C. D. C., Guimarães, A. G., Barreto, D. L., Silva, S. A. D., \& Huttner, L. B. (2010). Programa nacional de alimentação escolar: há segurança na produção de alimentos em escolas de Salvador (Bahia). Revista de Nutrição, 23(5), 801-811. https://doi.org/10.1590/S141552732010000500010

Carrasco, M., Guevara, B., \& Falcón, N. (2013). Conocimientos y buenas prácticas de manufactura en personas dedicadas a la elaboración y expendio de alimentos preparados, en el distrito de Los Olivos, Lima-Perú. Salud tecnol. vet, 1(1), 7-13. file:///C:/Users/tasiso/Downloads/104Texto\%20del\%20art\%C3\%ADculo-360-1-10-20140513\%20(1).pdf

Carvalho, C. T. D., Silva, A. K. O. D., Silva, M. J. S. D., \& Freitas, J. F. D. (2017). Proposta de reestruturação física da unidade produtora de refeição de organização militar. Hig. alim., 41-45. https://pesquisa.bvsalud.org/portal/resource/pt/vti-16706 https://pesquisa.bvsalud.org/portal/resource/pt/vti-16706

da Silva Júnior, D. I., \& Ferreira, M. C. (2007). Escala para avaliação de estressores ambientais no contexto off-shore oil (EACOS). Avaliaçao Psicologica: Interamerican Journal of Psychological Assessment, 6(2), 139-146. file:///C:/Users/tasiso/Downloads/Dialnet-EscalaParaAvaliacaoDeEstressoresAmbienta isNoContex-6674841.pdf

Devides, G. G. G. (2010). Análise do perfil socioeconômico e profissional de manipuladores de alimentos participantes de um programa de capacitação em boas práticas de fabricação, no município de Araraquara, SP. 100 f. Dissertação (mestrado) - Universidade Estadual Paulista, Faculdade de Ciências Farmacêuticas. http://hdl.handle.net/11449/88337.

de Freitas Saccol, A. L., Stangarlin, L., \& Hecktheuer, L. H. (2012). Instrumentos de Apoio para Implantação das boas Práticas em Empresas Alimentícias. Editora Rubio. 
dos Santos Ferreira, J., Souza Cerqueira, E., Silva Carvalho, J., Cardoso Oliveira, L., Reis Costa, W. L., \& Comastri de Castro Almeida, R. (2013). Conhecimento, atitudes e práticas em segurança alimentar de manipuladores de alimentos em hospitais públicos de Salvador, Bahia. Revista baiana de saúde pública, 37, 35. https://doi.org/10.22278/2318-2660.2013.V37.N0.A589

Góios, A., Martins, M. L., Ferreira, L., Nunes, A., \& Rocha, A. (2017). Conhecimentos de manipuladores de alimentos sobre segurança dos alimentos e alergias. Revista Higiene Alimentar, 31(264/265). https://docs.bvsalud.org/biblioref/2017/04/833022/264-265-sitecompressed-38-44.pdf

Instituto Brasileiro de Geograia - IBGE. Cidades. < https://cidades.ibge.gov.br/brasil/pb/picui/panorama>.

Leles, P. A., Pinto, P. D. S. A., \& Tórtora, J. C. D. O. (2005). Talheres de restaurantes self-service: contaminação microbiana. Hig. alim., 72-76. https://pesquisa.bvsalud.org/portal/resource/pt/vti-50168?lang=pt

Machado, A. P. D. J., Pascoal, T. D. S., \& Dias, R. M. F. (2018). Capacitação profissional e em boas práticas de manipuladores de restaurantes e lanchonetes localizados em IES de Salvador, BA. Hig. aliment, 43-47. https://pesquisa.bvsalud.org/portal/resource/pt/ens-36879

Mello, A. G. D., Gama, M. D. P., Marin, V. A., \& Colares, L. G. T. (2010). Conhecimento dos manipuladores de alimentos sobre boas práticas nos restaurantes públicos populares do Estado do Rio de Janeiro. http://dx.doi.org/10.4260/BJFT2010130100008

Melo, M. T. S. M., Santos, G. M. dos, Macêdo, M. C. F., Silva, B. L. dos S., Ripardo, S. R. P., Torres, B. L. M., Moura, A. C. C., Nunes, I. F. de O. C., Barreto, S. C. S., Paz, S. M. R. S., \& Carvalho, C. M. R. G. (2020). Segurança sanitária na produção de refeições em restaurantes de um mercado público no nordeste brasileiro. Research, Society and Development, 9(12), e2191210481. https://doi.org/10.33448/rsd-v9i12.10481

Messias, G. M. (2007). Hygienic-sanitary aspects, food handlers, managers and consumers. The situation of the fast food restaurants in the city of Rio de Janeiro, RJ. 120 f. Dissertação (Mestrado em Ciências Agrárias) - Universidade Federal Rural do Rio de Janeiro, Seropédica.

Moraes, P. L. "Contaminação dos alimentos". Brasil Escola. https://brasilescola.uol.com.br/biologia/contaminacao-alimentos.htm

Morais, A. S. M. D., Silva, L. D. A., Rocha, T. S. D., \& Macedo, L. D. S. O. (2016). Avaliação do conhecimento dos manipuladores de mercados públicos de Teresina-PI sobre boas práticas de manipulação de alimentos. Hig. aliment, 42-45. https://pesquisa.bvsalud.org/portal/resource/pt/biblio-834166?lang=es

Munhoz, Patrícia Marques. (2007). Qualidade higiênico-sanitária dos alimentos e avaliação sanitária dos conhecimentos sobre boas práticas por parte dos manipuladores de alimentos da rede municipal de ensino. 94 f. Dissertação (mestrado) - Universidade Estadual Paulista, Faculdade de Medicina Veterinária e Zootecnia- Botucatu, SP.

Oliveira, J. P. M., da Silva, S. S., da Silva Neto, J. C., Oliveira, J. M., da Silva, S. S., \& Maracajá, P. B. (2015). Avaliação da eficiência de higienização de mãos de manipuladores de alimentos. Informativo Técnico do Semiárido, 9(2), 11-15. https://editoraverde.org/gvaa.com.br/ revista/index.php/INTESA/article/view/3590

Oliveira, W. F. S. (2008). Application of food safety management system Study of case: Line of production frozen filet fish.110 f. Dissertação (Mestrado em Ciências Agrárias) - Universidade Federal Rural do Rio de Janeiro, Seropédica.

Oliveira, K. M. P. D., \& Silva, D. L. D. D. (2009). Conhecimento das merendeiras de Santa Fé, PR, sobre higiene e boas práticas de fabricação na produção de alimentos. Hig. alim., 39-46. https://pesquisa.bvsalud.org/portal/resource/pt/vti-14239

Paraiba. Lei $\mathrm{n}^{\mathrm{o}}$ 7.587, de 2 de junho de 2004. Institui a Lei da Qualidade Alimentar. Diário Oficial do Estado, João Pessoa-PB, 2004. http://www.normasbrasil.com.br/norma/lei-7587-2004-pb_144823.html

Pereira A. S. et al. (2018). Metodologia da pesquisa científica. UAB/NTE/UFSM. https://repositorio.ufsm.br/bitstream/handle/1/15824/Lic _Computacao_Metodologia-Pesquisa-Cientifica.pdf?sequence=1

São Paulo. (1999). Secretaria de Saúde. Coordenação dos Institutos de Pesquisa. Centro de Vigilância Sanitária. Portaria CVS no 6, de 10 de março de 1999. Dispõe sobre regulamento técnico de parâmetros e critérios para o controle higiênico sanitário em estabelecimentos de alimentos. Diário Oficial do Estado de São Paulo. http://www.cvs.saude.sp.gov.br/zip/E_PT-CVS-06_100399.pdf

Nascimento, L. L. R. D., Costa, M. M. A., Sousa, C. P. D., Silva, T. M. D., Gonçalves, G. F., \& Carvalho, C. T. D. (2017). Condições higiênico-sanitárias do cachorro-quente, comercializado por ambulantes no cinturão turístico da cidade do Natal-RN. Hig. aliment, 33-37.

Simon, D., \& Benedetti, V. P. (2016). Avaliação da contaminação microbiológica de esponjas utilizadas em serviços de alimentação da cidade de Marmeleiro PR. Hig. aliment, 73-77. https://pesquisa.bvsalud.org/portal/resource/pt/biblio-2555?lang=pt

Souza, G. C. D., Santos, C. T. B. D., Andrade, A. A., \& Alves, L. (2015). Comida de rua: avaliação das condições higiênico-sanitárias de manipuladores de alimentos. Ciência \& Saúde Coletiva, 20, 2329-2338. https://doi.org/10.1590/1413-81232015208.14922014

Souza, L. H. L. D. (2006). A manipulação inadequada dos alimentos: fator de contaminação. Hig. aliment, 32-39. https://pesquisa.bvsalud.org/portal/resource/pt/lil-456195

Stefanello, C. L., Linn, D. S., \& Mesquita, M. O. (2009). Percepção sobre Boas Práticas por cozinheiras e auxiliares de cozinha de uma UAN do Noroeste do Rio Grande do Sul. Vivências, 5(8), 93-98. http://www2.reitoria.uri.br/ vivencias/Numero_008/artigos/artigos_vivencias_08/Artigo_37.pdf

Teixeira, S. M. F., Oliveira, Z. M. C. D., Rego, J. C. D., \& Biscontini, T. M. B. (2010). Administração aplicada às unidades de alimentação e nutrição. In Administração aplicada às unidades de alimentação e nutrição (pp. 219-219). https://pesquisa.bvsalud.org/portal/resource/pt/lil-160464

Tondo, E. C., \& Bartz, S. (2011). Microbiologia e sistemas de gestão da segurança de alimentos. Sulina.

Trigo, V. C. (1999). Manual prático de higiene e sanidade das unidades de alimentação e nutrição. Livraria Varela. São Paulo - SP, Livraria Varela, 1999. 